\title{
Negociando la tierra: empresas extranjeras, minería a gran escala y derechos humanos en Colombia*
}

\author{
Negotiating land: Foreign Firms, Large Scale Mining and Human Rights \\ in Colombia \\ Negociando a terra: Empresas estrangeiras, mineração a grande escala \\ e Direitos Humanos na Colômbia
}

\author{
JUAN DAVID VELASCO \\ Centro de Recursos para el Análisis de Conflictos
}

FECHA DE RECEPCIÓN: 27 DE JUNIO dE 2013 • FECHA DE ACEPTACIÓN: 12 DE NOVIEMBRE DE 2013

Doi: dx.doi.org/10.12804/esj16.1.2014.07

Para citar este artículo: Velasco, J. D. (2014). Negociando la tierra: Empresas extranjeras, minería a gran escala y derechos humanos en Colombia. Estudios Socio-Jurídicos, 16(1), pp. 289-314. doi: dx.doi.org/10.12804/esj 16.1.2014.07

\section{RESUMEN}

La adquisición masiva de tierras por parte de empresas extranjeras en países africanos, asiáticos y latinoamericanos refleja una nueva fase del capitalismo global (Sassen, 2013). Colombia no ha escapado a esta lógica mundial del capitalismo, pues en la última década la influencia de las empresas extranjeras en el mercado de tierras ha sido notoria. En esa lógica, este artículo compara, desde un enfoque de Derechos Humanos, las prácticas de adquisición de tierras de tres compañías extranjeras que han explotado carbón a cielo abierto en La Guajira y Cesar. Los resultados indican que la formalidad de la propiedad agraria y las restricciones institucionales de las empresas -asociadas al gobierno corporativo, la participación en bolsa de valores y el veto de compradores internacionales-influyen significativamente en el respeto a los derechos humanos.

Palabras clave: adquisición de tierras, derechos humanos, Drummond, El Cerrejón, pluralismo jurídico.

* Este artículo fue presentado como ponencia para el VII Congreso Latinoamericano de Ciencia Política, organizado por la Asociación Latinoamericana de Ciencia Política (ALACIP) en Bogotá, los días 25 al 27 de septiembre de 2013.

** Politólogo de la Pontificia Universidad Javeriana con cursos de Maestría en el Instituto de Estudios Políticos y Relaciones Internacionales (IEPRI) de la Universidad Nacional de Colombia. Investigador del Centro de Recursos para el Análisis de Conflictos (CERAC). El autor agradece las múltiples observaciones y ayudas que recibió de Juan David González, Manuel Moscoso, Adriana Rocha, Manuel Gómez, Gina Galvis y Sofía León. También le agradece profundamente a Jorge Restrepo, Mauricio Romero, Francisco Gutiérrez, Juan Gabriel Gómez y Jenny Pearce por sus constantes llamados a la "prudencia intelectual". Correo electrónico: juangym1@hotmail.com 


\section{ABSTRACT}

The sharp increase in land acquisitions by foreign firms in African, Asian and Latin-American countries reflects a new phase of global capitalism. Colombia is no exception to this new trend of global capitalism, and in the last decade foreign companies have been visibly involved in the local land market. In this regard, this paper reviews from a Human Rights perspective the land acquisition strategies implemented by three foreign companies engaged in open-pit coal mining operations in La Guajira and Cesar. The results indicate that formality of land ownership and the institutional constraints on firms -related to corporate governance, being listed in stock markets and the veto power of international buyers- have a significant effect on the respect for Human Rights.

Key words: Drummond, El Cerrejón, Human Rights, land grabbing, legal pluralism

\section{RESUMO}

A aquisição massiva de terras por parte de empresas estrangeiras em países africanos, asiáticos e latino-americanos reflete uma nova fase do capitalismo global (Sassen, 2013). Colômbia não tem escapado a esta lógica mundial do capitalismo, pois na última década, a influência das empresas estrangeiras no mercado de terras tem sido notória. Nessa lógica, este artigo compara desde um enfoque de Direitos Humanos, as práticas de aquisição de terras de três companhias estrangeiras que têm explorado carvão a céu aberto na Guajira e Cesar. Os resultados indicam que a formalidade da propriedade agrária e as restrições

institucionais das empresas, associadas ao governo corporativo, a participação em bolsa de valores e o veto de compradores internacionais, influem significativamente no respeito aos Direitos Humanos.

Palavras-chave: Aquisição de terras, Direitos Humanos, Drummond, El Cerrejón, pluralismo jurídico. 


\section{Introducción}

El aumento de los precios de los alimentos, el crecimiento de la demanda mundial de biocombustibles y el descubrimiento de nuevas reservas de petróleo y carbón han dinamizado el mercado de tierras en países de África, Asia y Latinoamérica (Sassen, 2013, p. 26; Margulis, McKeon, Borras, 2013, p. 2; Cotula, Vermeulen, Leonard y Keeley, 2009, p. 5).

Se calcula que entre los años 2006 y 2010 las empresas y gobiernos extranjeros han comprado o arrendado doscientos millones de hectáreas de tierra en estos países (Land Matrix, 2012; Oxfam, 2012). La mayoría de compras o arrendamientos de tierras se han hecho para favorecer las inversiones en biocombustibles, cultivos alimentarios, silvicultura y minería (Anseuuw, Alden, Cotula y Taylor, 2012).

Colombia es uno de los países latinoamericanos en los que la adquisición de tierras por parte de empresas extranjeras ha sido más alta ${ }^{1}$ (Borras et al., 2012, p. 856). Para la muestra un botón: en los últimos quince años, dos compañías extranjeras dedicadas al negocio de exportación de carbón, como Drummond y El Cerrejón, adquirieron 130.000 hectáreas de tierra en los departamentos de La Guajira y Cesar.

La literatura internacional sobre "acaparamiento de tierras" (land grabbing) (Margulis, McKeon y Borras, 2013; De Shutter, 2011) sostiene que existe un vacío en la documentación de casos referidos a los países latinoamericanos (Borras et al., 2012), en especial, cuando de Derechos Humanos se trata (De Shutter, 2009). Es por ello que este artículo busca contribuir a este campo del conocimiento, comparando las estrategias de adquisición de tierras que utilizó Drummond en la vereda El Descanso del municipio de Codazzi, Cesar, y El Cerrejón, en el caserío de Roche ubicado en el municipio de Barrancas, departamento de La Guajira. ${ }^{2}$

Asimismo, para no limitar los estudios de caso a aspectos meramente descriptivos o normativos, ${ }^{3}$ se construirán un marco teórico y un índice

Los otros países identificados por Borras et al. (2012) son: Argentina, Brasil, Bolivia, Chile, Ecuador, Guatemala, Perú y Uruguay.

2 La evidencia empírica también incluye el caso de Intercor, la empresa que operaba en La Guajira antes de ser vendida a los diferentes accionistas que formaron posteriormente El Cerrejón.

3 Por ejemplo, los valiosos estudios elaborados por Indepaz (2011) tienen un componente descriptivo e inductivo fuerte que no permite extraer generalizaciones o inferencias causales. Así, el artículo de González Posso (2011, pp. 53-68), al centrarse exclusivamente en El Cerrejón, no permite 
que tienen como finalidad la identificación y medición de las variables más determinantes a la hora de examinar cuándo una empresa extranjera tiene incentivos para adquirir tierra sin menoscabar los derechos humanos de las comunidades que residen en las áreas donde se localizan los recursos minerales.

En función de estos objetivos, el artículo se ordenará de la siguiente manera: en la primera sección se hace una caracterización del universo jurídico que subyace al proceso de adquisición de tierras. En la segunda sección se describen los elementos que diferencian las "buenas" y las "malas" prácticas de adquisición de tierras, con el objetivo de aportar insumos conceptuales y metodológicos que permitan la escogencia del caso contrafactual de estudio.

Posteriormente, en la sección tres, se analiza cómo la estructura de propiedad agraria, las restricciones institucionales de las empresas y las características del mercado internacional del carbón inciden significativamente en los comportamientos que adoptan las empresas en materia de respeto y promoción de los derechos humanos (debida diligencia). A partir de la discusión teórica, se desarrolla en la sección cuarta un índice que permite diferenciar las buenas y las malas prácticas de adquisición empresarial de tierras.

Igualmente, en la sección cuarta, aplico los mecanismos explicativos observados a los casos de Drummond, Intercor y El Cerrejón. Y finalmente, en la quinta sección, enuncio las conclusiones de esta investigación.

\section{El pluralismo jurídico y lo complicado del caso colombiano}

A diferencia de los países desarrollados - donde el Estado cuenta y registra la propiedad rural, cobra impuestos y ofrece seguridad- en el tercer mundo, la falta de legitimidad de las instituciones políticas y la incapacidad del Estado para obtener el monopolio de la coerción han impedido que se desarrollen proyectos a gran escala de titulación y formalización de los derechos de propiedad sobre la tierra (Fitzpatrick, 2006).

La falta de censos catastrales y la tradición oral en las transacciones comerciales del campesinado, han generado en países tercermundistas un

observar variaciones en las prácticas empresariales de adquisición y administración de tierras en otras regiones como Cesar. 
'pluralismo jurídico' que dificulta la especificación y definición estatal de derechos de propiedad sobre los activos rurales (Fitzpatrick, 2006).

La dificultad radica en que la costumbre, la norma jurídica y la capacidad de coerción de un actor privado terminan constituyéndose en los mecanismos para hacer cumplir y respetar los derechos de propiedad (Fitzpatrick, 2006). Cuando la costumbre, la coerción privada y el derecho civil se superponen, aparece una confusión política y normativa que concede simultáneamente derechos de posesión, ocupación, tenencia y explotación a diferentes reclamantes sobre un mismo predio (Fitzpatrick, 2006).

Colombia, en los términos de Fitzpatrick (2006), tiene una legislación pluralista pues reconoce como sujetos con derechos a los propietarios, tenedores, poseedores y ocupantes, y además, reconoce distintos sistemas de propiedad: la privada (que gozan tanto personas naturales como jurídicas), la colectiva (que gozan minorías étnicas reconocidas como indígenas, palenqueros y afrodescendientes) y la estatal (los baldíos y el subsuelo).

En las regiones donde se localiza la riqueza mineral se exacerban los conflictos por la propiedad y la renta de la tierra, pues diferentes leyes y normas constitucionales compiten o se contradicen cuando (ver tabla 1) a) se busca extraer minerales en territorios colectivos, b) se busca extraer minerales en baldíos adjudicados a familias campesinas, y c) se necesita identificar los actores sociales que tienen derecho a la consulta previa. En ese orden de ideas, la contradicción de normas constitucionales y legales favorece la discrecionalidad con la que funcionarios de diferentes ramas del poder público tratan los aspectos relacionados con la definición de los derechos de propiedad sobre la tierra (Fitzpatrick, 2006).

\section{Como Caín y Abel: diferencias entre buenas y malas prácticas de adquisición de tierras}

Varios estudios han intentado incorporar un enfoque de derechos humanos para caracterizar los procesos de adquisición de tierras en términos de reasentamiento involuntario, desalojo forzado y desplazamiento de co- $^{-}$ munidades que residen en áreas concomitantes a la operación de empresas mineras (Indepaz, 2011). 


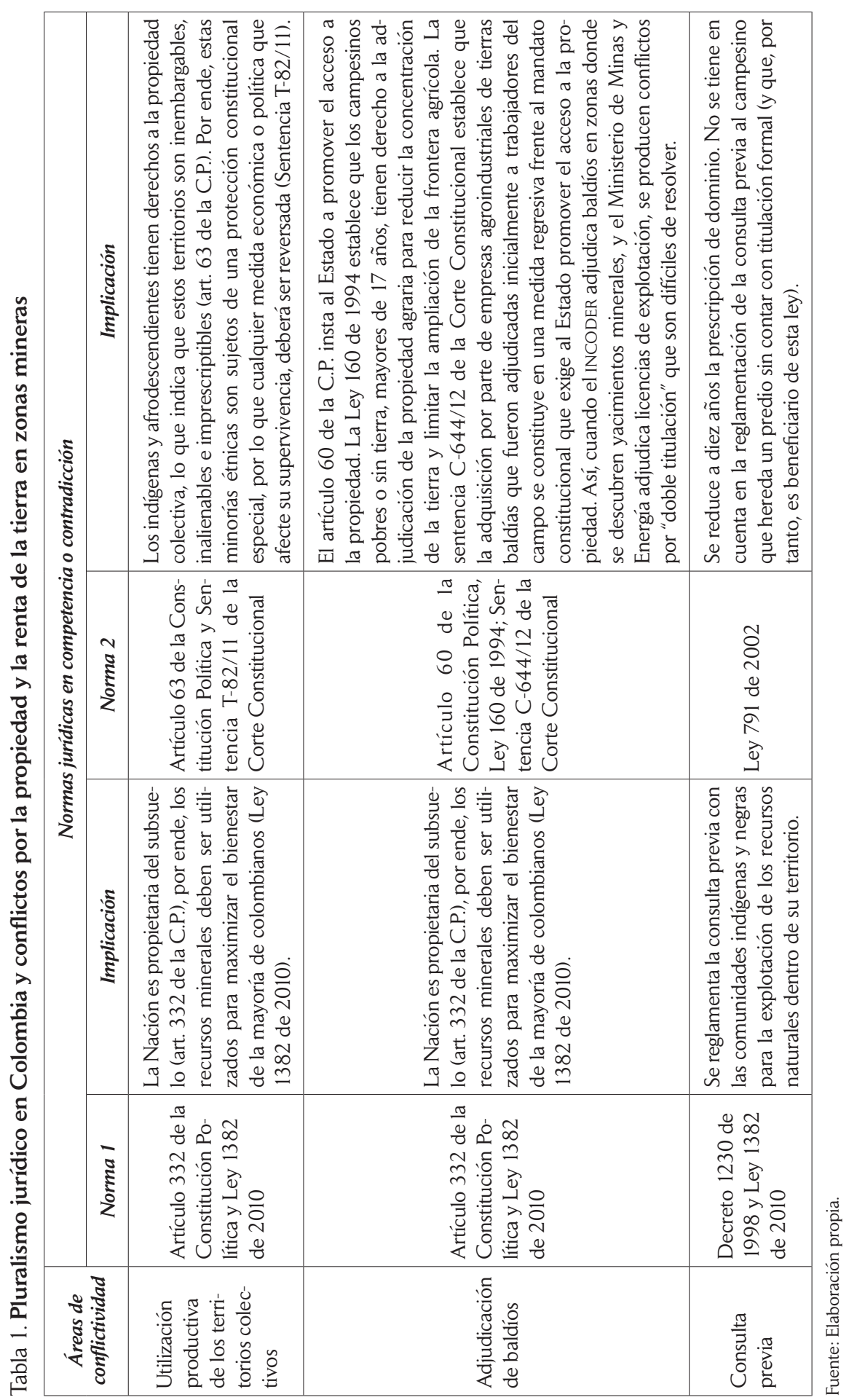


Sin embargo, trabajos como los de Duarte (2011, pp. 31-52) y González (2011, pp. 7-30) presentan sesgos de documentación y selección pues solo abordan los casos de empresas con malas prácticas en derechos humanos y no los de las empresas que manifiestan buenas prácticas (de hecho, no incluyen como fuentes de contrastación empírica la 'voz' de funcionarios y representantes de las empresas sindicadas de irrespetar los derechos humanos).

En parte, estos sesgos de selección se relacionan con la carencia de indicadores que permitan comparar las prácticas de adquisición de tierras. Por ello, en este artículo dichas prácticas se analizarán a partir de tres dimensiones: legitimidad, responsabilidad social y transparencia (ver tabla 2).

Estas tres dimensiones se extraen de la normatividad internacional que busca promover el respeto, la reparación y la rehabilitación de los derechos a la propiedad de comunidades que deben reasentarse de manera involuntaria. Se trata de los "Principios básicos y directrices sobre los desalojos y el desplazamiento generados por el desarrollo" elaborado por Naciones Unidas, el "Manual de reasentamiento de la Agencia de la ONU para los refugiados (ACNUR)" y el "Manual para la preparación de un plan de acción para el reasentamiento", elaborado por el Banco Mundial y la Corporación Financiera Internacional.

Por ejemplo, el "Manual para la preparación de un plan de acción para el reasentamiento" plantea que las transferencias comerciales de tierra deben contar con el consentimiento de venta de las comunidades. A este principio se le llamó legitimidad. En ese sentido, cuando no existe presión armada o institucional (amenazas de expropiación de abogados) en el proceso de compra y venta del predio, se considera la práctica como positiva y, cuando hay mediaciones coercitivas (expropiación, desalojo y expulsión del territorio), la práctica es negativa.

Por otra parte, el principio 16 de los "Principios básicos y directrices sobre los desalojos y el desplazamiento generados por el desarrollo" plantea que todos los reasentamientos deben incluir una oferta de reparación y rehabilitación amplia, basada en la indemnización, la relocalización a un nuevo hogar con servicios públicos, y la sostenibilidad de las comunidades. A este principio se le llamó responsabilidad social.

Así, cuando la oferta de reparación y rehabilitación incluye tres elementos (indemnización, acceso a servicios y adecuación del nuevo sitio 
de vivienda a las necesidades económicas y culturales), la práctica se juzga como positiva, y cuando la empresa reduce el proceso de adquisición a la mera compra del predio por precios mayores al avalúo comercial, la práctica se juzga como negativa. ${ }^{4}$

Finalmente,"el manual de reasentamiento de la Agencia de la ONU para los refugiados" y el "Manual para la preparación de un plan de acción para el reasentamiento" plantean que las empresas y el Estado deben verificar la tradición del inmueble para evitar que el sector privado sea un cómplice activo en la legalización del despojo o el abandono forzado de predios (Gutiérrez, 2010). A esta práctica se le llamó aquí "transparencia".

Así, cuando una empresa consulta al INCODER, a la Oficina de Registro e Instrumentos Públicos, a las notarías, a jueces municipales y a expertos locales se considerará la práctica como positiva. Y cuando una empresa no contrasta la información sobre la tradición del inmueble con diferentes agencias estatales, la práctica se juzgará como negativa. ${ }^{5}$

Tabla 2. Elementos que diferencian las prácticas de adquisición de tierras por parte de las empresas

\begin{tabular}{|c|c|c|}
\hline $\begin{array}{c}\text { Elemento } \\
\text { diferenciador }\end{array}$ & Buena práctica (debida diligencia) & Mala práctica \\
\hline \multirow[b]{2}{*}{ Legitimidad } & \multirow[b]{2}{*}{ Consulta para obtener consentimiento de venta } & i. Expropiación y desalojo \\
\hline & & $\begin{array}{l}\text { ii. Expulsión del territorio y des- } \\
\text { plazamiento forzado }\end{array}$ \\
\hline $\begin{array}{l}\text { Responsabili- } \\
\text { dad social }\end{array}$ & $\begin{array}{l}\text { Plantear como oferta de negociación la indem- } \\
\text { nización por lucro cesante, la relocalización a un } \\
\text { nuevo hogar con servicios públicos domiciliarios y } \\
\text { la financiación de nuevos proyectos productivos. }\end{array}$ & $\begin{array}{l}\text { Reducir el proceso de negocia- } \\
\text { ción a la mera compra del lote } \\
\text { por precios mayores al avalúo } \\
\text { comercial (precio minero). }\end{array}$ \\
\hline \multirow{2}{*}{ Transparencia } & $\begin{array}{l}\text { Verificar la tradición del inmueble con diferentes } \\
\text { agencias estatales: INCODER, Oficina de Instrumen- } \\
\text { tos y Registro Público y notarías. }\end{array}$ & $\begin{array}{l}\text { La verificación de la tradición } \\
\text { del inmueble se reduce a una } \\
\text { sola agencia estatal. }\end{array}$ \\
\hline & $\begin{array}{l}\text { Informar a las autoridades judiciales sobre casos } \\
\text { de adquisición de tierras por lavado de activos, } \\
\text { especulación y apropiación indebida de terceros. }\end{array}$ & $\begin{array}{l}\text { Se inician negociaciones de } \\
\text { compra-venta con testaferros } \\
\text { y propietarios de mala fe. }\end{array}$ \\
\hline
\end{tabular}

Fuente: Elaboración propia.

4 En el estudio de caso de El Cerrejón y Drummond (sección 4) se demostrará, por ejemplo, que las prácticas de adquisición de tierras pueden ser intermedias en cuanto a su transparencia.

5 Vale la pena hacer una precisión conceptual: de aquí en adelante utilizaré la palabra "debida diligencia" como sinónimo de respeto a los derechos humanos, es decir, como la adecuación del comportamiento empresarial a los principios de legitimidad, responsabilidad social y transparencia. 


\section{Negociando la tierra: minería a gran escala y derechos humanos}

En la literatura colombiana se encuentran dos perspectivas diferentes para abordar el problema del acaparamiento de tierras en municipios donde se ubican los recursos minerales. Una de estas perspectivas se enfoca en factores externos a la empresa, como el conflicto armado y el narcotráfico.

Según esta posición, los grupos armados no estatales (como los paramilitares), facilitan la llegada de empresas extranjeras al territorio por medio de intimidaciones, asesinatos selectivos y desplazamientos forzados que sirven para "despejar la zona" (Centro Internacional de Toledo para la Paz, 2012, p. 19; Programa de Naciones Unidas para el Desarrollo, 2011, pp. 255-262). Con el uso de la violencia, las empresas encuentran territorios despejados y pobladores atemorizados que están dispuestos a vender a un menor precio sus propiedades (Comisión Nacional de Reparación y Reconciliación, 2009).

Por otro lado, se han presentado perspectivas teóricas que se centran en los factores internos que caracterizan a las empresas. Por ejemplo, el estudio de Indermühle (2011, pp. 75-142) describe el funcionamiento de las 'transnacionales mineras' que operan en Colombia, desde la composición accionaria, la reputación internacional y la adopción de políticas de responsabilidad social empresarial (RSE, en adelante).

Indermühle (2011, pp. 75-142) deduce que la estructura accionaria de las compañías (pluralidad o concentración de dueños) y los escándalos que han tenido las multinacionales mineras en otros países (por contaminación medioambiental o asesinato de líderes sindicales) definen las relaciones de diálogo o confrontación que tendrán las empresas con las comunidades.

Aunque ambas perspectivas exhiben un poder explicativo, ninguna de ellas logra abarcar integralmente el fenómeno. Para ello es necesario que se tengan en cuenta tanto los factores exógenos (tabla 3) como los endógenos (tabla 4) en una misma narrativa explicativa.

Así, las empresas adquieren tierras de manera respetuosa con los derechos humanos (debida diligencia) cuando:

a. La estructura de propiedad de la tierra donde yacen los recursos minerales está formalmente definida (exógeno). 
b. Las restricciones organizacionales de la empresa los hace vulnerables a los escándalos por violación de DDHH (endógeno).

En esa lógica existen dos mecanismos exógenos a las empresas que afectan su predisposición para respetar los derechos humanos durante el proceso de adquisición de tierras. El primer mecanismo consiste en la activación de la trampa, es decir, cuando los políticos tienen acceso a información privilegiada porque ocupan un cargo público o tienen afinidades familiares o personales con funcionarios de agencias estatales encargadas de definir derechos de propiedad o de administrar activos rurales; estos (los políticos) se anticipan a la llegada de la empresa, de manera que compran masivamente predios para luego re-venderlos a la compañía por precios mucho más elevados al avalúo comercial.

Pero la trampa no viene solo de los políticos oportunistas. Cuando se esparce el rumor sobre la ubicación de recursos minerales en una vereda, se disparan los procesos de invasión de colonos usurpadores. ${ }^{6}$ La invasión puede ser ordenada y regulada por grupos armados no estatales (principalmente guerrillas) que buscan extraer rentas y ganar simpatías políticas con campesinos sin tierra que desaprueban la extranjerización de la propiedad rural.

Así mismo, la invasión puede ser espontánea, es decir, pobladores de cascos urbanos o campesinos de otras regiones de colonización pueden migrar de manera descoordinada y sin el apoyo logístico de organizaciones sociales o grupos armados no estatales. En ese sentido, tanto las invasiones ordenadas como las espontáneas aumentan la incertidumbre de las transacciones jurídicas al transformar el tamaño original de los lotes que se iban a negociar.

Igualmente, las empresas, aprovechando la Ley 1382 de 2010, se pueden comportar como agentes egoístas racionales (homo economicus), pues pueden solicitar al Ministerio de Minas y Energía que declaren los terrenos como de "utilidad pública e interés social" para que, mediante resolución administrativa, un juez municipal falle en favor de la expropiación y el desalojo

6 Alston, Libecap y Mueller (2010) dan buenos ejemplos de cómo en la región amazónica del Brasil se aumentaron las invasiones y el crecimiento de la frontera agrícola cuando el gobierno reconoció como sujetos con derechos legales a los colonos que explotaban baldíos. 
de los propietarios y ocupantes de lotes. Con esta argucia jurídica se pueden ahorrar millones de dólares en la compra de predios.

Tabla 3. Mecanismos exógenos a la empresa que afectan la debida diligencia

\begin{tabular}{|c|c|c|}
\hline Hipótesis & Mecanismos & Resultado \\
\hline \multirow{2}{*}{$\begin{array}{l}\text { Sin censo catastral y } \\
\text { sin títulos formales de } \\
\text { propiedad las empre- } \\
\text { sas no tienen incen- } \\
\text { tivos para adoptar la } \\
\text { debida diligencia. }\end{array}$} & $\begin{array}{l}\text { 1. Activación de la trampa: Los políticos compran } \\
\text { masivamente tierras para revenderlas a mayor } \\
\text { precio (especulación), los colonos invaden predios } \\
\text { y los propietarios desengloban lotes para capturar } \\
\text { rentas del proceso de negociación con la empresa. }\end{array}$ & $\begin{array}{l}\text { La empresa debe nego- } \\
\text { ciar con propietarios o } \\
\text { tenedores de mala fe, e } \\
\text { incluso, con testaferros. }\end{array}$ \\
\hline & $\begin{array}{l}\text { 2. Homo economicus: Para evadir los costos de } \\
\text { negociación, la empresa acude a instancias admi- } \\
\text { nistrativas y judiciales para expropiar y desalojar a } \\
\text { los ocupantes sin títulos de los predios. }\end{array}$ & $\begin{array}{l}\text { La empresa no obtiene } \\
\text { el consentimiento de } \\
\text { las comunidades asen- } \\
\text { tadas en el territorio. }\end{array}$ \\
\hline
\end{tabular}

Fuente: Elaboración propia.

Por otro lado, existen diversas restricciones institucionales que afectan la debida diligencia de las empresas (ver tabla 4). Una de ellas es la implementación del gobierno corporativo. Según la Organización para la Cooperación y Desarrollo Económico (2004), el gobierno corporativo presenta mejores indicadores de rendición de cuentas, transparencia y manejo del riesgo porque los procesos de toma de decisión no están concentrados en un gerente o en estructuras piramidales de decisión que no cuentan con contrapesos institucionales.

Tabla 4. Mecanismos endógenos a la empresa que afectan la debida diligencia

\begin{tabular}{|c|c|c|}
\hline Hipótesis & Mecanismos & Resultado \\
\hline \multirow{3}{*}{$\begin{array}{l}\text { La estructura geren- } \\
\text { cial de la empresa, la } \\
\text { participación en mer- } \\
\text { cados bursátiles y la } \\
\text { capacidad de veto de } \\
\text { compradores inter- } \\
\text { nacionales, afectan la } \\
\text { debida diligencia de } \\
\text { la empresa. }\end{array}$} & $\begin{array}{l}\text { 1. Auto-amarre: las empresas que } \\
\text { implementan el gobierno corpora- } \\
\text { tivo disponen de mayores mecanis- } \\
\text { mos de rendición de cuentas. }\end{array}$ & $\begin{array}{l}\text { Diferentes accionistas tienen incenti- } \\
\text { vos para solicitar información sobre } \\
\text { el cumplimiento de estándares de } \\
\text { respeto a los derechos humanos. }\end{array}$ \\
\hline & $\begin{array}{l}\text { 2. Aversión al riesgo: escándalos de } \\
\text { corrupción y violación de DDHH } \\
\text { afectan el precio de sus acciones } \\
\text { en la bolsa. }\end{array}$ & $\begin{array}{l}\text { La empresa busca una calificación fa- } \\
\text { vorable en las evaluaciones de riesgo } \\
\text { para no perder dinero por caída en } \\
\text { los precios de sus acciones en la bolsa. }\end{array}$ \\
\hline & $\begin{array}{l}\text { 3. Aversión al riesgo: los vetos o san- } \\
\text { ciones de proveedores o comprado- } \\
\text { res internacionales implican pérdidas } \\
\text { monetarias y baja de producción. }\end{array}$ & $\begin{array}{l}\text { La empresa evita sanciones y vetos de } \\
\text { compradores internacionales para no } \\
\text { perder dinero. }\end{array}$ \\
\hline
\end{tabular}

Fuente: Elaboración propia. 
Cuando las empresas implementan el gobierno corporativo imitan el comportamiento de Ulises al atarse al mástil para no acudir al canto de las sirenas (auto-amarre, según Elster, 2000). Para no cometer o repetir acciones que vulneren los derechos humanos, los accionistas solicitan periódicamente información sobre la adecuación de estrategias de compra de tierras a principios de legitimidad, responsabilidad social y transparencia (ver sección dos).

Por otra parte, las empresas que participan en mercados bursátiles son más sensibles y vulnerables a los escándalos por violación a los derechos humanos (Kappel, Schmidt y Ziegler, 2009; Guáqueta, 2006, p. 7). ${ }^{7}$ Cuando las empresas temen a que un escándalo deprecie el valor de sus acciones en la bolsa de valores, se activa el mecanismo de aversión al riesgo o aversión a la pérdida (Elster, 2010, pp. 238-255).

El mismo mecanismo de aversión al riesgo (Elster, 2010, pp. 238-255) se activa cuando las empresas tienen proveedores o compradores internacionales que rechazan las conductas violatorias a los derechos humanos (Guáqueta, 2006, p. 7). En este caso, las empresas para evitar una pérdida en la producción y una disminución en las ganancias, adecúan las estrategias de compra de tierras a principios de legitimidad, responsabilidad social y transparencia (ver sección dos).

\section{Los estudios de caso ${ }^{8}$}

\subsection{Cuando se pierde la materia: Drummond y la adquisición de tierras en Codazzi, Cesar (1995-2008)}

Desde los años setenta, en el departamento del Cesar, exactamente en el municipio de Codazzi, vereda El Descanso, había sido común que

7 Kappel, Schmidt y Ziegler (2009), basados en la metodología estadística "Event Study Analysis", observaron que las empresas estadounidenses e inglesas que cotizan en bolsa de valores redujeron el valor de sus acciones cuando se conocieron públicamente (reportajes en prensa) abusos a los Derechos Humanos en los que estuvieron vinculados. Según los autores, las empresas son sancionadas por los inversionistas pues las calificaciones de riesgo se vuelven desfavorables a la empresa.

8 Esta sección se realizó a partir de entrevistas semi-estructuradas a funcionarios de las compañías mineras, líderes sociales, representantes de organizaciones no gubernamentales y expertos locales. También se obtuvo información de la revisión de prensa y la consulta de fuentes documentales. 
colonos y familias tradicionales que ocupaban y explotaban los predios se dedicaran a la producción algodonera.

En la década de los setenta, Codazzi llegó a ser el principal productor de algodón en Colombia (Calderón, 2010). Durante los años ochenta disminuyó levemente el nivel de producción y a inicios de los noventa vivió la crisis más álgida de la historia algodonera por cuenta de la caída de los precios internacionales, el sobreendeudamiento de los pequeños productores y la falta de asistencia técnica por parte del Estado (Calderón, 2010). Una de las familias tradicionales propietaria de predios en la vereda El Descanso en Codazzi era los Campo Soto. Uno de los herederos del "clan familiar" era Rodolfo Campo Soto, quien fue alcalde de Valledupar (1992 -1994) y exgerente del Incoder. Cuando Rodolfo Campo Soto era alcalde de Valledupar, tuvo acceso a información privilegiada que indicaba que en la vereda El Descanso yacía carbón. Con esta información y con la quiebra de los pequeños y medianos productores algodoneros, los miembros de la familia Campo Soto (en especial, Rodolfo Campo Soto) comenzaron a comprarles los predios a sus vecinos a precios más bajos para posteriormente venderlos a Drummond a precios mayores al avalúo comercial. ${ }^{9}$

Por otro lado, durante la crisis algodonera muchos narcotraficantes y testaferros de los grupos paramilitares que operaban en la Serranía del Perijá comenzaron a comprar tierras. El caso más significativo fue el de Hugues Manuel Rodríguez, alias 'Barbie', un ganadero que fue pedido en extradición por Estados Unidos por el delito de narcotráfico. Alias 'Barbie' también estaba siendo investigado por la justicia colombiana por diversos delitos: conformación de grupos paramilitares, coautoría en el asesinato de una jueza, desplazamiento forzado de campesinos y coautoría impropia en secuestro de Elías Ochoa Daza, un ex alcalde de Valledupar (El Tiempo, 30 de agosto de 2008).

Pero los nuevos y viejos propietarios de los lotes de El Descanso no solo eran familias tradicionales como los Campo Soto; testaferros de los narcoparamilitares, como Hugues Rodríguez, y empresarios del campo que a pesar de estar quebrados no quisieron venderles sus predios a los Campo Soto o a alias 'Barbie'. Con el rumor de que existían grandes yacimientos de carbón en esta vereda, aparecieron en el año 1997 colonos usurpadores

9 Entrevista con experta (reserva de nombre) en Bogotá, el 21 de agosto de 2013. Esta información es corroborada por El Tiempo (30 de agosto de 2008). 
que invadieron los terrenos manifestando que tenían derechos de posesión sobre la tierra porque residían allí con antigüedad y porque habían explotado económicamente esos predios. La llegada de colonos usurpadores precipitó los conflictos horizontales sobre la tierra, es decir, los problemas de convivencia entre vecinos por definición de linderos y por englobe de lotes. ${ }^{10}$ Durante estos conflictos la estructura de tenencia de la tierra se modificó sustancialmente.

Cuando Drummond buscó la licencia de explotación, se enfrentaba a una condición de informalidad en los derechos de propiedad rural. En primera instancia, porque muchos predios fueron adquiridos de mala fe por la familia Campo Soto al aprovechar la información privilegiada que tenían como funcionarios públicos, y porque capitalizaron la quiebra de los pequeños productores de algodón adquiriendo aproximadamente 2.300 hectáreas de tierra a través de la compra a bajos precios.

En segunda instancia, se calcula que el testaferro narcoparamilitar $\mathrm{Hu}-$ gues Rodríguez, compró aproximadamente 8.000 hectáreas en esta vereda donde yacía carbón (El Tiempo, 30 de agosto de 2008). Estos predios, aunque no es claro que hayan sido adquiridos mediante el despojo violento, sí representaban claras operaciones de lavado de activos. ${ }^{11}$

Y en tercera instancia, con la invasión de docenas de familias sobre los predios que eran principalmente explotados por los empresarios algodoneros que se rehusaron a vender ${ }^{12}$ se agudizaron los conflictos de propiedad y se modificó la estructura de la tenencia de la tierra, pues muchas familias comenzaron a englobar y desenglobar lotes como una estrategia rápida de redefinición de linderos.

Ante este panorama, Drummond, que ya había ganado la licitación que le concede derechos de explotación sobre la mina El Descanso en Codazzi en 2007, debía comprar tierras a terceros que la adquirieron de mala fe, a colonos invasores y a testaferros de paramilitares.

Finalmente, Drummond les compró tierras a personas que mostraron sus títulos de propiedad mediante escritura pública por precios mayores al

10 Entrevista a la investigadora Sofía León, el 16 de abril de 2013 en Bogotá.

11 A juzgar por el principio de honestidad (sección 2), Drummond falló a la hora de verificar la tradición de los inmuebles que iba a negociar.

12 Según la investigadora Sofía León (en entrevista el 16 de abril de 2013), los predios invadidos no fueron los de la familia Campo Soto sino los de las familias que no quisieron venderles. 
avalúo catastral (precio minero). ${ }^{13}$ En estas compras, Drummond no incluyó como oferta negociadora la indemnización por lucro cesante, la relocalización de las personas en viviendas con servicios públicos domiciliarios y la financiación de proyectos productivos.

Igualmente, Drummond compró haciendas relacionadas indirectamente con Hugues Rodríguez (alias 'Barbie') y buscó la adjudicación de las 2.700 hectáreas que poseía la familia Campo Soto por medio de un litigio y una resolución administrativa de nivel ministerial que declarara los predios que tenía la familia Campo Soto como de "utilidad pública" (El Tiempo, 30 de agosto de 2008). Cuando se declararon los predios de la familia Campo Soto como de "utilidad pública" y se autorizó la expropiación, esta familia y Drummond finalmente negociaron. ${ }^{14}$ Con respecto a los invasores, Drummond les compró a menor precio del avalúo catastral para evitar conflictos ulteriores por reclamaciones de las familias invasoras.

Estas tres estrategias de adquisición de tierras no probaron debida diligencia, dado que la compañía negoció predios sin triangular la información sobre la tradición de los inmuebles, se valió de una herramienta jurídica como el desalojo - por tratarse la minería de una actividad de utilidad pública- $\mathrm{y}$ aprovechó los conflictos intercomunitarios para acceder a tierras a un menor precio, pues a los antiguos propietarios o invasores que probaron tenencia u ocupación tenían incentivos de vender rápido y a menor precio.

Las prácticas de adquisición de tierras de Drummond, sin respeto a los derechos humanos, se explican por la estructura informal de propiedad agraria en la vereda El Descanso, pues las invasiones de colonos y la adquisición masiva de predios por parte de políticos oportunistas y criminales dificultaron las negociaciones legítimas y transparentes.

Por otra parte, la carencia de un gobierno corporativo, ${ }^{15}$ la concentración de la estructura accionaria, ${ }^{16}$ la no participación en mercados bursátiles

13 Entrevista con experta (reserva de nombre) en Bogotá, el 21 de agosto de 2013.

14 En esta investigación no se pudo constatar el precio al cual Drummond le compró a los propietarios de lotes de la familia Campo Soto.

15 Indermühle (2011: 95) observa que en la página web de Drummond y en sus comunicados de prensa existe bastante discrecionalidad con respecto a la publicación de información financiera, la declaración pública de compromisos de responsabilidad social y la elaboración de informes de sostenibilidad. En la interpretación sugerida aquí, esto se debe a que no existe una estructura gerencial de tipo gobierno corporativo que los incentive a rendir cuentas periódicamente y a proyectar la imagen de "empresa responsable".

16 Drummond es una empresa limitada - en el sentido jurídico del término- cuyo propietario 
y la inexistencia de compradores internacionales que estuvieran interesados en los derechos humanos ${ }^{17}$ impidieron que se incentivara a la empresa a adecuar su comportamiento a los principios de legitimidad, responsabilidad social y transparencia, pues no existían costos monetarios visibles que afectaran el nivel de rentabilidad de sus operaciones productivas y comerciales.

\subsection{De oscuro a castaño: la evolución de las prácticas de adquisición de tierras en el caserío de Roche, La Guajira}

La historia sobre los procedimientos de adquisición de tierras por parte de las compañías mineras en Roche, caserío ubicado en el sur de Barrancas (municipio de La Guajira), se puede dividir en tres períodos: 1) antes de la implementación de estándares internacionales en reasentamiento de comunidades - cuando operaba la empresa Intercor- (1997-2002), 2) durante la formulación del Plan de Acción de Reasentamiento (PAR) que se basó en los lineamientos del Banco Mundial y la Corporación Financiera Internacional (2003-2008), y 3) durante la implementación del PAR por parte de El Cerrejón (2009-2012).

En el primer periodo, la empresa Intercor negoció directamente la compra-venta de predios con integrantes de la comunidad de Roche, compuestos principalmente por campesinos (alguno de ellos tenían relaciones de parentesco con indígenas de la etnia wayúu). Las negociaciones presentaban una oferta económica que era relativamente mayor al avalúo catastral producido por el Instituto Colombiano Agustín Codazzi (el precio minero).

En la mitad de los casos, las transacciones tuvieron lugar con el consentimiento fundado del vendedor y con compensaciones basadas en los precios de la tierra en el mercado. Y en la otra mitad, donde los habitantes ocupaban baldíos sin títulos de propiedad, Intercor recurrió al instrumento legal de desalojamiento porque el gobierno nacional había dado en concesión dichos territorios.

es Gary Neil Drummond, y sus hijos, que son residentes de Alabama, Estados Unidos (Indermühle, 2011, p. 95). Los propietarios siempre han sido "los herederos hombres" de Henry E. Drummond, el fundador de la empresa en 1935.

17 Drummond solo opera en Estados Unidos (como productor de coque mercante en Alabama, y negociante inmobiliario en Miami) y Colombia (como productor de carbón a cielo abierto). Todos sus negocios son cerrados, es decir, todas las redes de proveedores y compradores tienen un vínculo estrecho con Gary Neil Drummond. Esto hace que la empresa no se vea presionada por inversionistas o proveedores internacionales para que cumplan estándares de derechos humanos. 
En este período de tiempo (1997-2002) los procedimientos de adquisición de tierras eran informales y directos: cada abogado o negociador de Intercor ofrecía una suma de dinero al propietario de los predios. Esta estrategia generó conflictos comunitarios porque no todos los habitantes estaban de acuerdo con vender sus predios, pues varios líderes argumentaron que con la venta de sus tierras se perdía su tradición cultural y se perdían las fuentes de ingreso derivadas de la ganadería y el pastoreo.

A pesar de la oposición de un sector de las comunidades campesinas, Intercor pudo comprarles los predios a quince familias. No obstante, estas familias gastaron rápidamente el dinero que les dio Intercor sin haber aprovechado ese capital para la inversión en una vivienda nueva y en un negocio que les permitiera garantizar su subsistencia económica. La perseverancia de varios líderes campesinos que se rehusaron a vender, el fracaso económico de las quince familias que vendieron sus predios y el descontento de los desalojados unieron a la comunidad campesina de Roche para rechazar los procedimientos de adquisición de tierras por parte de Intercor mediante movilizaciones sociales, protestas y ocupaciones a la línea férrea.

Así mismo, la oposición mayoritaria de la comunidad campesina al procedimiento de adquisición de tierras por parte de Intercor atrajo el apoyo de activistas internacionales en derechos humanos y organizaciones no gubernamentales que visibilizaron sus demandas ante diferentes sectores de la opinión pública nacional e internacional.

Con la mala reputación de Intercor, la oposición de las comunidades campesinas a la minería y la necesidad de aumentar las inversiones en tecnología, los antiguos propietarios de Intercor decidieron vender en 2000 y 2001 su participación en la mina al consorcio integrado por dos subsidiarias de Billiton Company, una subsidiaria de Anglo American y una subsidiaria de Glencore, conformando así la Sociedad Cerrejón Zona Norte S.A.

Posteriormente, en 2002, subsidiarias de Anglo American, BHP Billiton y Glencore adquieren el 50\% restante de El Cerrejón zona norte mediante la compra de la participación de Exxon Mobil en Intercor, convirtiéndose en dueños únicos por partes iguales de la compañía. En 2006, Glencore vende su participación a la empresa europea Xstrataplc, cuyas subsidiarias son actualmente propietarias de El Cerrejón junto con subsidiarias de BHP Billiton y Anglo American. La compra de Intercor por parte de compañías de diferentes países condujo a que la nueva empresa, llamada El Cerrejón, 
implementara un gobierno corporativo en el cual se debían establecer diferentes estándares internacionales de promoción, respeto y remedio de los derechos humanos, entre ellos los Principios Ruggie y los Principios Voluntarios (Indermühle, 2011: 125-127).

Así, el gobierno corporativo se implementó con un par de propósitos: uno, fomentar la rendición de cuentas entre los gerentes y los accionistas de la empresa de manera que los propietarios pudieran controlar la adopción de medidas impopulares - como, por ejemplo, desplazar a las comunidades por efectos de la construcción de botaderos o contaminar su hábitat-y dos, mejorar la imagen de la compañía y reorientar su impacto en la sociedad a través de la elaboración periódica de informes de sostenibilidad que trazaban metas y desafíos concretos en la relación con los derechos humanos. ${ }^{18}$

Durante los años 2003 a 2008 (segundo periodo) se diseñó un Plan de Acción de Reasentamiento (PAR) para la comunidad de Roche bajo los lineamientos de la Corporación Financiera Internacional (2004). El PAR, para evitar las relaciones informales de compraventa de predios, buscó institucionalizar las relaciones de intercambio con las comunidades a partir de una consulta previa y la realización de un censo y una línea de base que contabilizó el número de lotes, las familias que los ocupan y las cabezas de ganado por hectárea (inventario de activos, en general).

El PAR buscó incorporar una visión de sostenibilidad en los procesos de relocalización de las 25 familias que debían abandonar involuntariamente el territorio. En esa lógica, diseñó una estrategia en cuatro frentes:1) pagos de indemnización por los bienes afectados o por cuestión de lucro cesante, 2) reubicación de familias en nuevas residencias -incluyendo instalación de servicios públicos domiciliarios y atención psicosocial-3) oferta de capacitaciones dirigidas a los adultos para que aprendan a utilizar productivamente una hectárea de terreno que les adjudican por haberse reasentado, y 4) cupos escolares y becas educativas para niños y adolescentes de las comunidades.

La aplicación de estándares internacionales en derechos humanos en el periodo 2003-2008 mejoró la reputación de la compañía con los campesinos y pudo mitigar la herencia de desentendimientos que había dejado Intercor con su fallida política de adquisición de predios en el caserío de Roche.

18 Entrevista con funcionario del área de "Estándares Sociales y Relacionamiento Internacional" de El Cerrejón, en La Guajira, el 5 de diciembre de 2012. 
Sin embargo, la luna de miel entre El Cerrejón y las comunidades duró hasta el año 2009, cuando la compañía compró 600 hectáreas en el municipio de Fonseca para iniciar la fase de los reasentamientos. En este año surgen los primeros conflictos por la propiedad o titulación de los predios. Según líderes comunitarios, la compañía no realizó adecuadamente el censo poblacional, pues no tuvo en cuenta a varias familias que eran semi-nómadas o que tenían una antigüedad de posesión sobre los predios.

En contraste, los funcionarios de El Cerrejón ${ }^{19}$ argumentaron que, con posterioridad al censo realizado en 2003, aparecieron nuevas familias y que de manera oportunista decidieron dividir los lotes para aumentar el número de propietarios que se beneficiarían directamente de las rentas que obtendrían de su inclusión en el PAR que trazó la compañía. ${ }^{20}$ De igual manera, surgieron conflictos por la renta de la tierra. Ocho familias se negaron al reasentamiento porque consideraron que las indemnizaciones, la retribución económica por el lucro cesante de la ganadería y la devolución de tierra en Fonseca no eran proporcionales al número de hectáreas poseídas, ocupadas o explotadas originalmente. ${ }^{21}$ Por ejemplo, había casos en los que una familia ocupaba más de 50 hectáreas de tierra y la devolución por parte de la compañía era de una hectárea para desarrollar proyectos productivos. Además, hubo casos en los que familias que tenían aproximadamente 300 cabezas de ganado terminaron oponiéndose a las negociaciones puesto que no tenían incentivos para participar en proyectos de emprendimiento empresarial que fueran diferentes a la ganadería y la agricultura.

A pesar de la oposición de las ocho familias que se rehusaron a participar del PAR, en el año 2012 se inicia la fase de relocalización y estabilización en Fonseca de las diecisiete familias que estuvieron de acuerdo con vender y reasentarse. Por su parte, las ocho familias disidentes iniciaron un ciclo de protesta social, reclutando otros miembros de la comunidad Roche y Chancleta. La protesta de estas ocho familias se tradujo principalmente en acciones de ocupación a la línea férrea por donde se transporta el carbón

19 Entrevista con funcionario del área de "Estándares Sociales y Relacionamiento Internacional" de El Cerrejón, en La Guajira, el 5 de diciembre de 2012.

20 Para comprender esta situación, véase el mecanismo de activación de la trampa en la sección tres.

21 Entrevista con líderes sociales en el municipio de Barrancas, La Guajira, el 26 de diciembre de 2013 . 
hacia el puerto de embarque. Adicionalmente, estas han encontrado el apoyo de activistas europeos de derechos humanos como ASK, FIAN, Colombia Solidarity Campaign y organizaciones no gubernamentales como Indepaz y Aviva Chomsky.

La oposición persistente de estas familias al proceso de reasentamiento condujo a que en el año 2012 El Cerrejón solicitara al Ministerio de Minas y Energía la emisión de una resolución administrativa que declara los predios de Roche como de utilidad pública e interés social. Igualmente, El Cerrejón interpuso una demanda de expropiación, la cual fue aceptada por un juez de San Juan del Cesar. El juez ordenó la entrega anticipada de los derechos de posesión de los predios de Roche, la cual deberá realizarse in situ el 27 de agosto de 2013 (véase principio de legitimidad en la sección dos).

Al final, diecisiete de las veinticinco familias que estaban en la meta del PAR se han reasentado en el municipio de Fonseca. El Cerrejón aplicó estándares internacionales de derechos humanos para estos grupos familiares por introducir una visión de sostenibilidad y mejora de la calidad de vida de las familias campesinas que vendieron (es decir, cumplieron con el principio de legitimidad y responsabilidad social visto en la sección dos). Por otra parte, las ocho familias que se opusieron fueron expropiadas y tuvieron que desalojar por el fallo judicial que se amparó en la resolución administrativa del Ministerio de Minas y Energía.

Esta ambivalencia impide que se juzgue la política de adquisición de tierras de El Cerrejón como completamente respetuosa de los derechos humanos. Sin embargo, sería injusto calificarla como carente de debida diligencia, pues la compañía aplicó medidas orientadas al cumplimiento de los principios de legitimidad, responsabilidad social y transparencia.

En conclusión, El Cerrejón adquirió tierras de manera más diligente porque el censo catastral que mandó a realizar le redujo la informalidad en la propiedad de los lotes, aunque no pudo evitar que se activaran los aparentes comportamientos oportunistas de algunos campesinos. Igualmente, la participación en mercados bursátiles, la implementación de un gobierno corporativo y la capacidad de veto de los compradores internacionales de carbón (Indermühle, 2011, pp. 99-100) volvieron más sensible y vulnerable a la empresa frente a los escándalos de derechos humanos que podrían surgir de una política de tierras ilegítima, irresponsable y deshonesta. 


\subsection{Una propuesta de medición: el índice de respeto a los derechos humanos}

Para comparar los tres casos se construyó un índice (ver tabla 5) que mide el peso que tienen las diferentes variables exógenas y endógenas en la adopción de principios de legitimidad, responsabilidad social y transparencia por parte de la empresa durante los procesos de adquisición y compra de predios.

Este índice operacionaliza las variables exógenas (informalidad de la propiedad rural y tradición del inmueble) y endógenas (gobierno corporativo, participación en bolsa de valores y capacidad de veto de compradores internacionales) que afectaron el comportamiento de las tres empresas extranjeras que fueron objeto de estudio en materia de derechos humanos.

Los resultados indican que la formalidad en la propiedad agraria (fruto de la elaboración de censos catastrales) y las restricciones institucionales de las empresas, cuando implementan gobiernos corporativos y cotizan acciones en la bolsa de valores, explican cuándo estas tienen más incentivos de respetar los derechos humanos durante el proceso de adquisición de predios. 
Tabla 5. Índice que permite explicar si la práctica de adquisición de tierras de una empresa fue con debida diligencia

\begin{tabular}{|c|c|c|c|c|c|c|c|}
\hline \multirow[b]{2}{*}{ Uanes- } & \multirow[b]{2}{*}{ Valath } & \multirow[b]{2}{*}{ 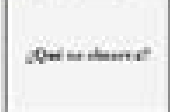 } & \multirow[b]{2}{*}{ Inle bes } & \multirow[b]{2}{*}{ 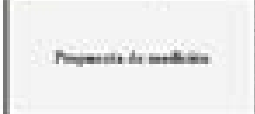 } & \multicolumn{3}{|c|}{ Cam } \\
\hline & & & & & 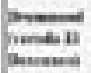 & 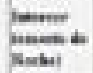 & 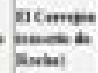 \\
\hline \multirow{5}{*}{ Bnityon } & \multirow{3}{*}{ 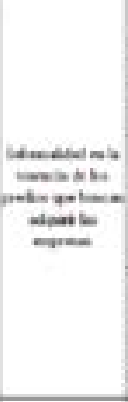 } & 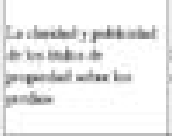 & 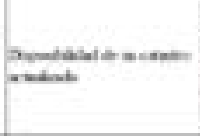 & 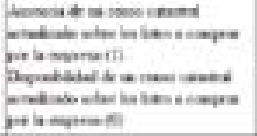 & I & i & in \\
\hline & & 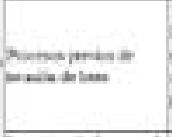 & 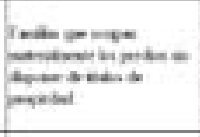 & 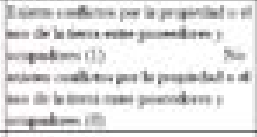 & 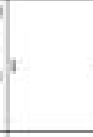 & $\beta$ & F \\
\hline & & 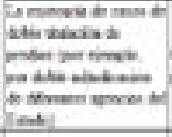 & 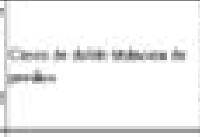 & 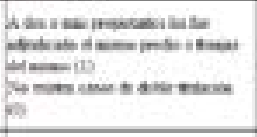 & it & 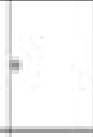 & F \\
\hline & \multirow{2}{*}{ 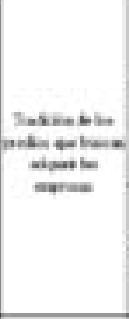 } & mocidiakian & 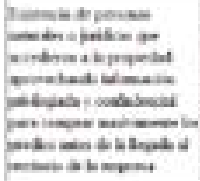 & 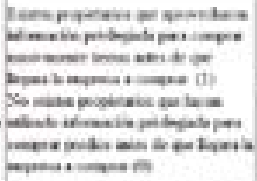 & 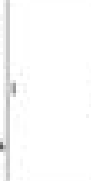 & 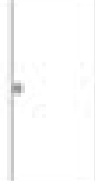 & 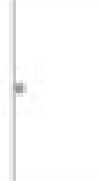 \\
\hline & & 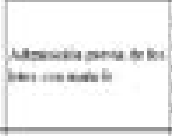 & 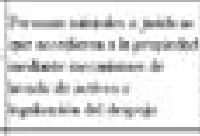 & 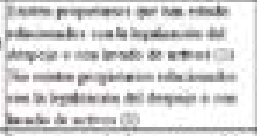 & 1 & 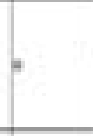 & 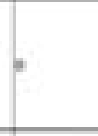 \\
\hline \multirow{4}{*}{ Entoven } & 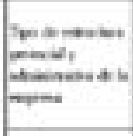 & 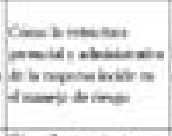 & 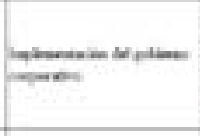 & 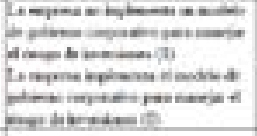 & a & 8 & $m$ \\
\hline & 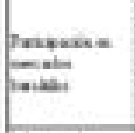 & 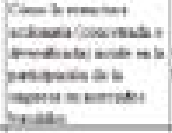 & pabiaks & 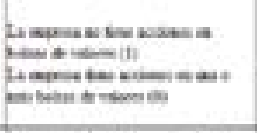 & 4 & 7 & i \\
\hline & 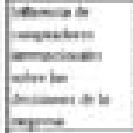 & 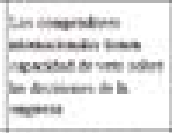 & Cowitot a row in ks & 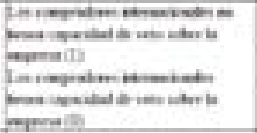 & I & f & 7 \\
\hline & Raswes ib & 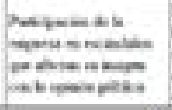 & 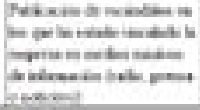 & 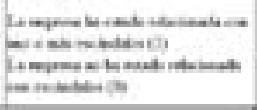 & 4 & 1 & 1 \\
\hline \multicolumn{5}{|c|}{ Rind } & tis & 127 & $10=$ \\
\hline
\end{tabular}

* Valores $>0,0<0,4$ significan que la empresa adquirió tierras respetando los Derechos Humanos.

** Valores $>0,41<0,99$ significan que la empresa adquirió tierras vulnerando los Derechos Humanos.

Fuente: Elaboración propia. 


\section{Conclusiones}

La formalidad en los derechos de propiedad rural y las restricciones institucionales de las empresas explican cuándo estas tienen incentivos para incluir un enfoque de derechos humanos en sus estrategias de adquisición de tierras (ver tabla 6).

Tabla 6. Comparación de casos de Drummond, Intercor y El Cerrejón

\begin{tabular}{|l|l|l|l|}
\hline \multicolumn{2}{|l|}{} & \multicolumn{2}{c|}{ Restricciones institucionales de la empresa } \\
\cline { 3 - 4 } & & Altas & Bajas \\
\hline \multirow{2}{*}{$\begin{array}{l}\text { Nivel de informalidad en la es- } \\
\text { tructura de propiedad de los } \\
\text { lotes donde yacen los minerales }\end{array}$} & Alto & $\begin{array}{l}\text { Ausencia de debida dili- } \\
\text { gencia: Drummond (Vere- } \\
\text { da El Descanso) e Intercor } \\
\text { (caserío de Roche) }\end{array}$ \\
\cline { 2 - 4 } & Bajo & $\begin{array}{l}\text { Debida diligencia aco- } \\
\text { tada: caso de El Cerrejón } \\
\text { (caserío de Roche) }\end{array}$ & \\
\hline
\end{tabular}

Nota: La clasificación de los casos se hizo de los resultados numéricos obtenidos en el índice (ver tabla 5).

Fuente: Elaboración propia.

Cuando las empresas no elaboran censos catastrales para identificar la estructura de propietarios y los tamaños de los lotes se crean incentivos para que políticos oportunistas compren predios masivamente antes de la llegada de la empresa al territorio, y así lograr vendérselos a precios más elevados del avalúo comercial. Asimismo, crea incentivos para que colonos invasores lleguen a ocupar los predios en donde subyace el recurso mineral (ya sea espontáneamente o por presión y coordinación de grupos armados no estatales que tienen intereses en sabotear la actividad de la empresa). Esta situación le ocurrió a Drummond en la vereda El Descanso, y en menor medida a Intercor en el caserío de Roche.

Igualmente, cuando la empresa no implementa un modelo de gobierno corporativo, no participa en mercados bursátiles y no tiene compradores internacionales de carbón que sean críticos frente a la debida diligencia, es probable que no sientan 'aversión al riesgo' de irrespetar los derechos humanos durante su práctica de adquisición de tierras, pues los costos de implementar medidas de debida diligencia (lo que en la sección se llamó principios de legitimidad, responsabilidad social y transparencia) son más 
altos que los costos económicos y reputacionales que le implican los escándalos de derechos humanos.

Es por ello que la diferencia cualitativa entre El Cerrejón y Drummond, en cuanto a los métodos de adquisición de tierras, radica en los esfuerzos que realizó El Cerrejón para conocer la estructura de la propiedad en Roche (a través de un censo catastral) y en las diferencias de cada empresa en términos de sus restricciones institucionales: por un lado, El Cerrejón cotiza acciones en bolsa de valores, implementa un gobierno corporativo y tiene compradores que desde Australia y Alemania le exigen el respeto a los derechos humanos, mientras que en el lado de Drummond e Intercor (cuando existía), estas variables institucionales y del mercado de internacional de carbón estuvieron ausentes.

\section{Referencias}

\section{Bibliográficas}

Alston, Libecap y Mueller (2000). Land Reform Policies, The Sources of Violent Conflict and Implications for Deforestation in the Brazilian Amazon. Journal of Environmental Economics and Management, 39, 162 - 188.

Anseeuw, W., Boche, M., Breu, T., Giger, M., Lay, J., Messerli, P. y Nolte, K. (2012). Transnational Land Deals for Agriculture in the Global South: Analytic Report based on the Land Matrix Database International Land Coalition. Berna/Montpellier/Hamburgo: CDE/CIRAD/GIGA.

Borrás, S. M., Franco, J. C., Gómez, S., Kay, C. y Spoor, M. (2012). Land Grabbing in Latin America and the Caribbean. Journal of Peasant Studies, 39(3-4), 845-872. Calderón, W. (2010). Bonanza y crisis del algodón en Cesar, 1950-2010, Bogotá: Banco de la República.

Centro Internacional de Toledo para la Paz (2012). Actores armados ilegales y sector extractivo en Colombia. Bogotá: Centro Internacional de Toledo para la Paz.

Comisión Nacional de Reparación y Reconciliación (2009). El despojo de tierras y territorios: una aproximación conceptual. Bogotá: Comisión Nacional de Reparación y Reconciliación (CNRR), Instituto de Estudios Políticos y Relaciones Internacionales (IEPRI), Universidad Nacional de Colombia.

Corporación Financiera Internacional, Departamento de Medio Ambiente y Desarrollo Social (2002). Manual para la preparación de un plan de acción para el 
reasentamiento. Recuperado de http://www.prosap.gob.ar/docs/UAS-PlanParaReasentamiento.pdf

Cotula, L., Vermeulen, S., Leonard, R. y Keeley, J. (2009). Land Grabor Development Opportunity? Agricultural Investment and International Land Deals in Africa. Londres: International Institute for Environment and Development.

De Schutter, O. (2011).How Not to Think of Land Grabbing: Three Critiques of Large-Scale Investments in Farmland. Journal of Peasant Studies, 38(2), 249-279.

Duarte, N. (2011). La Responsabilidad Social Empresarial. ¿Realidad o utopía? En Indepaz (ed.). Megaminería y reasentamientos forzados (pp.31-51). Bogotá: Editorial Punto de Encuentro.

Elster, J. (2000). Ulises y las sirenas. Estudios sobre racionalidad e irracionalidad. México: Fondo de Cultura Económica.

Elster, J. (2010). La explicación del comportamiento social. Más tuercas y tornillos para las ciencias sociales. Barcelona: Gedisa.

Fitzpatrick, D. (2006). Evolution and Caos in Property Rights Systems: The Third World Tragedy of Contested Access. The Yale Law Journal.

Guáqueta, A. (2006). Operaciones en zonas de conflicto y gobernabilidad frágil: guías prácticas para empresas en sectores no extractivos. Bogotá: Fundación Ideas para la Paz. Gutiérrez, F. (2010). Land and Property Rights in Colombia: Change and Continuity. Nordic Journal of Humans Rights, (28), 230-261.

González, L. (2011). Desalojos forzados, reasentamientos involuntarios y Derechos de las Comunidades. En Indepaz (ed.). Megaminería y reasentamientos forzados (pp.7-30). Bogotá: Editorial Punto de Encuentro.

González Posso, C. (2011). Reasentamientos de comunidades en áreas vecinas a la mina Cerrejón. Algunos criterios para superar las trampas de la pobreza. En Indepaz (ed.). Megaminería y reasentamientos forzados (pp.53-69). Bogotá: Editorial Punto de Encuentro.

Indermühle, S. (2011). Transnacionales Mineras en Colombia. En Indepaz (ed.). Megaminería y reasentamientos forzados (pp.77-142). Bogotá: Editorial Punto de Encuentro.

Kappel, V., Schmidt, P. y Ziegler, A. (2009). Humans Right Abuse and Corporate Stock Performance - An Even Study Analysis. Recuperado de http://www.eea-esem.com/ files/papers/EEA-ESEM/2009/854/wp.pdf

Land Matrix (2012).The Land Matrix, Beta Version: The online public data base on land deals (ILC/CIRAD/CDE/GIGA/GIZ). Recuperado de http://landportal.info/ landmatrix

Margulis, M., McKeon, N. y Borras Jr., S. (2013). Land Grabbing and Global Governance: Critical Perspectives. Globalizations, 10(1), 25-46. 
Organización para la Cooperación y Desarrollo Económico (2004). Principios del Gobierno Corporativo de la OCDE. Recuperado de http://www.oecd.org/daf/ca/ corporategovernanceprinciples/37191543.pdf

Oxfam (2012). Land and power: the growing scandal surrounding the new wave of investments in land. Recuperado de http://www.oxfam.org/sites/www.oxfam.org/files/ bp151-land-power-rightsacquisitions-220911-en.pdf

Programa de Naciones Unidas para el Desarrollo (2011). Colombia rural. Razones para la esperanza. En PNUD (ed.). Informe nacional de desarrollo humano. Recuperado de http://www.pnud.org.co/sitio.shtml?apc=aCa020-11 $\& x=65970 \& s=$;\#. UrN1NtJDs18

Sassen, S. (2013). Land Grabs Today: Feeding the Disassembling of National Territory. Globalizations, volume (10), 25 - 46.

\section{Periodísticas}

$30 \%$ de mina de carbón a cielo abierto más grande de Latinoamérica es de narcoparamilitar. (2008, 30 de agosto). El Tiempo. 